\title{
An Overview of China's Ethnic Groups and Their Interactions
}

\author{
Shenghai He \\ Department of Ethnology and Sociology, Inner Mongolia University, Hohhot, China \\ Email: zjchst@126.com
}

How to cite this paper: He, S. H. (2017). An Overview of China's Ethnic Groups and Their Interactions. Sociology Mind, 7, 1-10. http://dx.doi.org/10.4236/sm.2017.71001

Received: November 26, 2016 Accepted: December 26, 2016 Published: December 29, 2016

Copyright $\odot 2017$ by authors and Scientific Research Publishing Inc. This work is licensed under the Creative Commons Attribution International License (CC BY 4.0).

http://creativecommons.org/licenses/by/4.0/

\begin{abstract}
Since the founding of the Communist Party of China in 1921, the relations among China's many ethnic groups have undergone incessant changes. This article will discuss the impact of China's ethnic minorities on China as a whole, and additionally illuminate specific intra-ethnic relations, that is, the ways in which cultural minorities affect one another. We will explore four stages in the development of China's intra-ethnic interactions, three historical and one anticipated stages: namely, 1) Revolutionary Stage (1921 to 1966), 2) Political Ethnic Relations (1967 to 1977), 3) Economic Interactions (1978 to early $21^{\text {st }}$ century), 4) Anticipated Overcoming of Residual Biases. The background and characteristics of each developmental stage will be explained.
\end{abstract}

\section{Keywords}

Intra-Ethnic, Chinese Revolution, Ethnic Identity, National Identity

\section{Literature Review on China's Intra-Ethnic Relations}

There are 56 distinct ethnic groups distributed throughout mainland China, including five sizable "autonomous regions". The Han majority represents $92 \%$ of the total population, the remaining $8 \%$ being composed of 55 ethnic minorities, including the Zhuang, Uighur and Tibetan, Mongolian, and Hui populations, all of which have had centuries of dealings with one another. Their ethnic relations have played a significant role in shaping China's history, society and politics. Scholars have sought to understand these intra-ethnic relations from different perspectives.

Luo Kanglong (1998) suggests that Chinese intra-ethnic relations are of four types: equitable, cooperative, symbiotic and acculturative, among which equitable intra-ethnic relations predominate. These features are the result of long historical development and may be observed today (Luo, 1998). Ma Zongbao (2001) finds four characteristics shared by Hui (Muslim) and Han people in Chinese history: 1) cross residence; 2) equality and 
mutual benefit in political life; 3) economic complementarity; and 4) cultural affinity (Ma, 2001). Yang Jianxin (2002) stresses the incompleteness of ethnic equality and the limitations of ethnic solidarity (Yang, 2002). Ding Longzhao (2003) says that current intra-ethnic relations can be understood via biological symbiosis theory, which treats ethnic groups organically as dependent on each other, as manifested in the fields of politics, economics and culture (Ding, 2003).

As for the literature treating China's intra-ethnic relations, many focus on Chinese history, fewer on current conditions. Research perspectives are relatively narrow, concentrating on the interaction between fixed ethnic minorities and the Han people, e.g., giving us pairs such as Tibetan/Han, Uyghur/Han, Mongolian/Han, or they fix on a certain region, such as Tibet, Xinjiang, Inner Mongolia and so on. Such micro-investigations are abstract and lack pragmatic significance. It is respectfully submitted that the four-stage approach outlined the following sheds more light and proves more useful, namely 1) Revolutionary Stage (1921 to 1966), 2) Political Ethnic Relations (1967 to 1977), 3) Economic Interactions (1978 to early $21^{\text {st }}$ century), 4) Anticipated Overcoming of Residual Biases.

\section{Revolutionary Stage (1921 to 1966)}

Since 1921, the CPC has viewed ethnic harmony as critical for the success of the Chinese Revolution (Zhou, 1997). That revolution is generally conceived as ongoing. Ethnic minorities have always been important elements in that Revolution, contributing manpower, material resources and even human lives. Following are some typical examples.

During the War of Resistance against Japan in northwestern China (1931-1945), the "Hui Culture Promotion Association" persuaded the Muslim Chinese to donate a military airplane to support the resistance. From 1938 to 1939, over 50,000 fur coats, a large amount of medicine and 10 tons of white board paper were sent by HCPA to Yanan to support the Eighth Route Army (Li, 2001). In 1937, masses of Tibetan monks from Qilian and Gansu Province volunteered to collect necessary provisions and donate 215,000 silver dollars. In 1940, the people in Labuleng Tibetan area in Gansu Province each donated a penny, enough to buy 30 airplanes on sudden notice (Tang, 1995).

In southwestern China, approximately 20,000 young men from different ethnic groups in Yunnan, Guizhou and Sichuan joined the First Red Army, the Second Army and the Sixth Army. Five or six thousand young men of different minorities in Guizhou Province, including the Miao, the Yi and the Bai, enlisted in the Red Army (Members of Writing Groups, 2001).

In central part of the south, ethnic minorities in Hunan Province like the Tujia, Hui and Bai, actively took part in the famous "Long March." According to available statistics, 6900 minority people in Longshan County, 300 in Tujia and Miao in Baojing County and 3,700 in Cili County joined the Red Army and moved north to resist Japanese troops (Chen, 2005). In 1938, 8,000 Miao soldiers marched up to the front line in Hubei and launched a fierce fight which resulted in a complete victory (Ling, 1988).

In northeastern China, under the leadership of Kim Il-Sung, Koreans engaged in guerrilla tactics in Baishan, handing a powerful defeat to the Japanese invaders. In the 
War of Liberation, more than 60,000 Koreans participated, more than 3550 lost their lives, along with 4313 martyrs in Yanbian (Zheng, 2011).

Such Revolutionary actions were some of the most vital supporting factors in the creation of a new China. After the founding of the People's Republic, in order to consolidate the Revolutionary gains of the War, the Chinese Communist Party instituted political, economic and cultural reforms and polices for minorities, laying a solid foundation for ensuing intra-ethnic relations.

As stipulated in "Common Program of Chinese People's Political Consultative Conference", all ethnic groups in PRC share equal rights; discrimination, oppression and segregation are banned. Having been involved in fighting against common enemies so as to shape the People's Republic of China, various ethnic groups constitute in idealistic terms one large and diverse family whose maxim is mutual cooperation and advancement.

\section{Political Ethnic Relations (1967to 1978)}

From 1958 onward, China underwent two tumultuous decades, which were severely affected by "Cultural Revolution" between 1966 and 1976. During this period, China's intra-ethnic relations entered the second phase, namely, the Political. Interaction among ethnic groups was politically mandated.

\section{a. The Background of Political Intra-Ethnic Relations}

In the period of "Cultural Revolution," two counterrevolutionary groups led by Lin Biao and Jiang Qing (one of "Gang of Four") criticized and denied the achievement of the ethnic innovations China had made. The article "Current Ethnic Affairs and Class Struggle in China" (Red Flag, 1964) proposed that the essence of ethnic reality is class struggle, in accord with general principles of Marxism/Leninism. No credit was given to particular ethnic distinctions or contributions. Therefore, the ethnic social policies were deemed of no account.

Ethnic rights and autonomy, recognized since the founding of the PRC, were misconstrued as divisive. China's long-standing ethnic policies were also accused of undermining the leadership of the Party. Autonomous agencies were said to be opposed to socialism and a regression into capitalism. In order to preserve nationality, the social strata should remain forever uniform. In the final analysis, national struggle was a matter of class struggle and the debate was stuck in the mud of class warfare (He, 2005). We will discuss events following the Great Cultural Revolution what it is.

\section{b. Characteristics of Political Ethnic Intra-Relations}

1. The great historical regression

During the period of Political ethnic relations (1966-1976), China's social policies entered a period of tension. Ethnic characteristics lost much of their prestige and support, which tended to weaken the unity, solidarity and mutual cooperation inherited from Revolutionary phase. Han chauvinism, disrespecting ethnic customs and traditions and, in some cases, abolishing those customs and traditions, harmed indigenous peoples. Finally, the politics-oriented social movement paralyzed industrial and agricultural production and national trade, leading ethnic regional economies to stagnate.

2. Ethnic Insularity 
There were four main factors that contributed to ethnic insularity. The first was systematic management. "The People's Commune" had become the predominant mode of rural production. "Agricultural Cooperatives" were in charge of all things, including farming, distribution, and supply. People, like potatoes, were put into "the cooperative's bag," within which, individuals were regionally confined and often lost the ability to interact with other groups. Independent communications among ethnic groups were restricted, leading to cultural isolation. On the political level, slogans like "to rebel is justified", "doubt everything and knock down everything" were promoted by political radicals, hindering and stifling ethnic exchanges. In terms of culture, the policy of amalgamation and unity resulted in the attempted assimilation of minorities to a homogeneous world without any distinguishing features. At the psychological level, minorities found it was expedient to behave with tact and circumspection in asserting their distinctness and their relations with other groups.

\section{Abnormality}

Under the principle of class struggle, ethnic religious and traditional customs were not respected. Many substantial policies were abrogated in the period and ethnic minorities were regarded as backward. It was easy to perceive discrimination in official ethnic policies. Under high-handed administration, ethnic interactions became unfruitful, and intra-ethnic communications were nominal. Practically speaking, nearly every ethnic group was subjected to discrimination, and even some elites were persecuted. Ethnic interactions were oppressive, defensive, hostile and unpleasant. Normally, ethnic interactions are not self-absorbed, but social and gregarious. People in the period in question were wholly dominated by the Agricultural Cooperative, which hindered ethnic communication. Normal convivial interactions were not possible.

\section{Market Interactions (1978 to Early $21^{\text {st }}$ Century)}

After the Gang of Four was crushed in 1976,"the Third Plenary Session of the Eleventh Central Committee" conducted by Deng Xiaoping in 1978, promoted large-scale debate about whether praxis is the sole criterion for testing truth. The debate upheld again the ideological principles of emancipating the mind and winnowing truth from facts and brought order out of chaos. The Third Plenary Session of the Eleventh Central Committee decisively discarded the slogan "Take class struggle as the key link", and made the strategic decision to concentrate instead on socialist modernization, an historical turning point. Deng's "Resolutions of Certain Historical Issues of the Party since the foundation of PRC" and an editorial, "Ethnic Issues Are Not Class Issues" (People's Daily, on July 15, 1980) proposed that China's revolutionary socialism should include and benefit from working people of all ethnic groups. Ethnic disputes are mere empirical contingencies, not contradictions in the classless society which Marxism-Leninism envisions (State Ethnic Affairs Commission, CCCP Party Literature Research Office, 1990). This rectified the misunderstanding of the ethnic issue, allowing emphasis on multi-ethnic cooperation in the creation of a market-based economic system. The 1978 watershed established that China's new economy would not be a wholly planned or scientific economy but a market system with appropriately "Chinese characteristics".

Since then China's planned economy has been evolving into a market economy, ad- 
justing and disposing of resources largely through Adam Smith's "the invisible hand."

Market-oriented Ethnic Interaction means exchanges among ethnic groups based on market supply and demand extending to all parts of social life. This systemic economic transformation has spurred trade and cooperative ventures. We see, then, that Intraethnic relations reach progressively more sophisticated stages of development (Jin, 2007: p. 607). Currently, we recognize five categories of productivity associated with minorities.

1. Ethnic Specialties

The main products in northwestern regions are fruits, including grapes, apples, honeydew melons, and other vegetative commodities such as cotton, sugar and tobacco. Significantly, traditional medicine (Tibetan, Wei, and Dai) is now sought in urban areas. According to the preliminary statistics conducted by State Ethnic Affairs Commission, there were more than 200 ethno-medical enterprises which generated 5.5 billion Yuan (approximately 0.84 billion dollars) in 2004. They are gradually stepping into the international market (Yang, 2010: p. 235). Ethno-medical brands and enterprises are well known in China, and products such as Qizheng, Jinzhu Tibetan Medicine, and Mengwang Mongolian Medicine are exported to European and American distributors.

2. Unique Livestock Products

Six vast prairies flourish in China, most of which are in minority areas, covering $3,245,800 \mathrm{~km}^{2}$. Herbivorous livestock is raised in abundant grass valleys. Over two representative decades, the minority contribution to the production of meat, milk and plush leather was $26.4 \%, 34.8 \%$ and $56.3 \%$ respectively (Yang, 2010: p. 228). Livestock products have become a substantial part of the commercial exchanges of Han people and various minorities.

3. Cultural Products

Thirty-eight projects of intangible cultural heritage in China are listed by UNESCO of which 14 were created by minorities. In 2014, out of a total of 1219 intangible heritage protection projects, $433 \%$ or $34.9 \%$ are the responsibility of ethnic minorities. There are 1986 inheritors of intangible heritage, of whom 524 are ethnic minorities. Exquisite handicrafts enjoy wide popularity, including those of the Oroquen, (including water bottles, photo frames, flower pots, insoles, jewelry, birchbark boats), the Mongolians (clothes, jewelry and foodstuffs), the Baoan (famous broadsword) the Tibetan (tangka) and the Miao (silver ornaments). Minority cuisines and languages are widely spread. Striking costumes, batik, embroidery, painting, cut-paper illustrations, sculpture, and bamboo weaving enter into market, promoting the economic development of minorities.

4. Mineral Resources in Western Ethnic Areas

In 2014, President Xi Jinping recognized that ethnic areas are legitimate sources of minerals, water, ecological wealth and cultural enrichment. The amount of coal from western minorities accounts for $61.9 \%$ of the total. 160 minerals are mined there. Of more than 130 verified minerals, 30, including rare earth, vanadium, titanium and copper, can be found in west. According to the Second Evaluation Report on Oil and Gas, oil resources in four basins accounted in 2014 for $27.6 \%$ of the total. At the end of 2000, natural gas reserves in China were 0.29 billion $\mathrm{m}^{3}$, of which western areas con- 
tained $80 \%$. Water resource reserves in west account for $85.5 \%$ of the whole. Wind has the potential to generate 3.226 billion kw power. In practice, 0.253 billion power is generated by wind, mainly in Inner Mongolia, Xinjiang and Hexi Corridor in Gansu (Yang, 2010: p. 216).

\section{Tourism}

Beautiful scenery, well-preserved frescoes in caves, unique religious architecture, and distinctive ethnic customs and traditions in ethnic areas have become important destinations for tourism. Major attractions are the Silk Road, Desert Journey, Qinghai-Tibet Plateau, and Mongolian Grasslands. There are thirty national tourist spots and fourteen special tourist spots confirmed by Chinese National Tourism Administration, of which $40 \%$ have ethnic and religious significance. Tourism has become an important factor in stimulating minority prosperity.

There are generally four aspects of Market Interaction.

1. Complementarity

Many unique products made by minorities have become important modes of communication with the Han majority. At the same time, Han technology and rich managerial experience are reshaping ethnic areas. In Hulunbuir prairie, herdsmen use natural gas to cook instead of traditional cow dung, solar power to watch TV and motorcycles or cars to travel. Obviously, the economic patterns of ethnic minorities and Han people are complementary.

2. Reliability

Han and ethnic peoples are dependent on one other. Minority development needs Han's technical sophistication and Han people rely on minority cultural and mineral resources. Examples are "West-to-East Gas Transmission Pipeline Project" and "Southto-North Water Transfer". Market Interactions make it possible for the Han and ethnic groups to exchange resources, which plays a vital role in upgrading industrial structure, increasing profits, strengthening competitiveness in trade and bolstering economic cooperation among ethnic groups. Market Interactions make for a united and complete China.

\section{Competition}

Competition is a fundamental aspect of a market economy. There is no doubt that fair competition can enhance skills, and boost economic capacity, leading to self-reliance and enterprising spirit. At present, competition in Market Ethnic Interactions do not harm ethnic interests, but stimulates common interests, such as national and ethnic development and people's wealth. Competition should be conducted on the basis of equality, unity, cooperation and harmony to foster social and national goals (Jin, 2007: p. 279). Monopolization is detrimental to fair competition, and any form of corruption undermines harmonious relations.

\section{Problems}

"Survival of the fittest" remains the classic watchword of the market economy. In the transition to the market model, Chinese people are learning to accept the inevitable aspect of risk. As efficient players prosper, per the "law of the jungle" inefficient operators fall by the wayside. That is the price we pay for progress. There are other challenges. Many villages remain supported by a single industry such as straw weaving, leaving 
them vulnerable to changes in production and demand for that commodity. Backward technology, harsh natural conditions, fragile ecosystems, frequent natural disasters and lack of sustainable and efficient production are among the most notable. These aspects contribute to the economic gap between Han and regional populations and exacerbate existing inequalities (the "Matthew effect") (Yang, 2010: p. 162). The more urbanized Han people make it difficult for rural minorities to find jobs when they relocate to urban areas.

We may conclude that so long as we continue to preserve minority populations in China, we will face difficulties associated with inequalities. Realistically, we cannot have it both ways. China is not trying to grow regional populations to such an extent that they might rival the Han. Such a policy would be folly and self-defeating in light of the goal of folk protection and intangible resources. We want to preserve our cultural legacies. It follows that there will almost certainly remain disparities in China's demographic. All that can reasonably be expected is to nurture the indigenous peoples, provide decent housing and education, and design a progressive pathway for ambitious individuals to pass from village life to urban life if sufficiently motivated.

\section{Anticipated Overcoming of Ethnic Biases}

At present, China's ethnic intra-action is gradually completing its trajectory from Market driven relations to positive social relations. Huang Guoguang, a Taiwanese scholar, suggests a healthy society is just like family; members have a responsibility to meet others' needs, with care, safety and a sense of belonging. In this process, people may transcend the idea that each person should manage his/her own business well, when one is in need, others naturally volunteer their services to help (Huang, 1988). In this pattern, in addition to material help, members share mutual profit, shared identity, absolute honesty and sense of belonging. Overcoming regional and ethnic provincialism should include the following elements.

1. Improvement on Rule of Law

With the improvement of Rule of Law, the tendency to damage or destroy other ethnic groups' interests will be discouraged. People can learn that ethnic relations can be complementary rather than hostile and destructive. The phase of partial unity, limited cooperation and equality in Market Interactions will ultimately be surpassed. History has proven that "ethnic equality and national unity are fragile and unstable and will be subject to interference and damage without legal protection" (Jin, 2007: p. 128). Meanwhile, a strong, scientific and efficient social management is an important protection of social interactions. With the advent of effective Rule of Law, respect for others becomes more important than reactions based on class, race or regionalism, and violations of ethnic rights and interests are gradually reduced.

Of course, this improvement depends on a relatively high degree of integration; the traditional focus on the way to make one's own ethnic group gain advantage shifts to the considerations of fairness and justice. "Profit" behavior is replaced by "reciprocity".

\section{Cultural Tolerance}

Ethnicity is a constellation of shared characteristics such as culture, language, religion, and tradition. When China's intra-ethnic interactions adopt a familial paradigm 
(hearkening back to Hexie), People of all ethnic groups treat each other as kin, having trust and common interests. In this way, society is characterized by coordination and inclusiveness, so there is no conflict of between various sub-cultural systems, and no clash of political ideas and political beliefs among various social strata. The difference between sub-cultures can be adjusted through ethnic communication or mutual adaptation so as to promote the interests of entire community. In fact, it presents as a totality with differences in the unity (Fei, 2009).

3. Continuous Development of Economy

Ethnic minorities are active participants in such national enterprises as the "One Belt and One Road" plan. More opportunities for ethnic minorities are provided and more specialties of ethnic economy are presented. Besides, unique tourist, animal, port, and mineral resources together with other advantages, have lent strong support to our national economy. Moreover, with the continuous improvement of autonomous region system, the government accelerates economic development of ethnic areas through special fiscal and preferential policies dedicated to ethnic minorities. It can be predicted that the poverty of ethnic minorities will be relieved continuously, reducing substantially the gap between Han and other peoples.

\section{The Change of the Traditional Ethnic Living Pattern}

The sixth national census shows the total number of ethnic minorities in China has reached 15,229,000, increased by 5,445,000, over the number of 9,784,000 in 2005, with $1,089,000$ in average annual growth (Chi, 2014). It is self-evident that ethnic minorities inhabit different locales: Tibetans in Tibet, Uygurs in Xinjiang, Mongolians in IMAR, etc. In the case of the Mongolians, they were mainly concentrated in the central and western parts of Inner Mongolia before 2000, but now have gradually spread to the whole country. The proportion of Mongolians in big cities like Beijing, Shanghai, Shenzhen and Guangzhou has been increasing. In Beijing, ethnic minorities from all over the country have formed the "Xinjiang village", the "Dai village", the "Hui Street" and other wards or districts.

Population mobility and urbanization represent Chinese modernity. It will be a long process for regional minorities to urbanize, but that is the path of the future. In fact China's minorities have always lived in conjunction with the Han people. Therefore, it no longer surprises us to note that different ethnic groups abide in the same neighborhood, or that languages and residential barriers are reduced or eliminated. Ideally we will preserve ethnic identities while harmful, unproductive and artificial tensions tend to fade away (Zheng, 2011).

\section{Intermarriage}

With ethnic populations flowing and intermingling, people will have more opportunities to communicate and cooperate. As a result, intermarriages will become more common. Current statistics shows that the number of some minorities' intermarriages exceeds that of endogamy. Take Oroqen, Hezhe and Tatar for example. The intermarriage rates of these three ethnic groups are respectively $86.19 \%, 84.13 \%$ and $76.20 \%$. In the same year, the mixed household of ethnic minorities and Han people in Inner Mongolia accounted for $11.7 \%$ of the total number (Ma, 2004). In recent years, the rate of intermarriage in Alxa county remains over 1/3 of the total marriage of that year ( $\mathrm{He}$, 
2014). With the existence of a large number of intermarriages, interaction between ethnic groups becomes more important, as China progresses to its own version of Marx's classless society. Of course, all these ethnic relations and interactions remain fundamental expressions of the Revolutionary stage because People's Republic of China is founded on the basis of a Revolutionary mission.

\section{Conclusion}

Since the founding of new China, intra-ethnic relations have evolved. In Revolutionary Stage, to seek the independence of the nation-state, ethnic groups combined their strength to promote national liberation. In the "Cultural Revolution" period, the interactions between Han majority and minorities were naturally politicized, and may thus be termed Political/Ethnic Relations. Interactions based on supply and demand leading to interdependence and competitiveness formed a third phase which may be denominated "Economic Interactions". As Anticipated Overcoming of Residual Biases emerges, people will share profit, national identity, practical honesty and sense of belonging.

\section{Acknowledgements}

The article is funded by Inner Mongolia Social Science Research Project: "Research on the Construction of Harmonious Ethnic Relations in Inner Mongolia from the Perspective of National Identity", Item No.: 16B01.

\section{References}

Chen, T. L. (2005). Great Contribution Ethnic Minorities in Hunan Made to Anti-Japanese War. Journal of Minzu University of China, 32, 5-10.

Chi, S. J. (2014). An Analysis of the Flux Tendency of the Minority Floating Population in China. Journal of Beijing Police College, 5, 37-42.

Ding, L. Z. (2003). The State of Symbiosis-A New Perspective in Which to Understand the Relations between All the Chinese Nationalities. Journal of Inner Mongolia Normal University, 32, 55-58.

Fei, X. T. (2009). The Collection of FeiXiaotong's Papers (p. 147). Hohhot: Inner Mongolian People's Publishing House.

He, L. Q. (2005). History of Chinese Ethnic Policy (p. 201). Beijing: People's Publishing House.

He, S. H. (2014). Research on Flowing Model of Intermarriage in Western China-The Case in Alxa County. Inner Mongolia Social Sciences, 35, 175-180.

Huang, G. G. (1988). Social Interaction and Face: the Game of Chinese Thrones (pp. 7-56). Taibei: Juliu Book Company.

Jin, B. G. (2007). A Survey on Ethnic Interaction Theory (p. 76). Beijing: The Publishing House of Minzu University of China.

Li, W. (2001). Hui People's Contribution to the War of Anti-Japanese (p. 94). Lanzhou: Gansu People's publishing House.

Ling, Y. (1988). The Light of Life Is for Ever-In Remembrance of Chen Congwen (Four). People, 9, 14-17.

Luo, K. L. (1998). Study on Intra-Ethnic Relations (p. 76). Guiyang: Guizhou Ethnic Publishing House.

Ma, R. (2004). Sociology of Ethnicity: Sociological Study of Ethnic Relationship (p. 453). Beijing: 
Beijing University Press.

Ma, Z. B. (2001). The Historical Characteristics of the Interaction between Hui and Han Nationalities. North West Minorities Research, 4, 79-86.

Members of Writing Groups (2001). The Experience of First Front Army of the Chinese Workers' and Peasants' Red Army's Long March (p. 94). Beijing: People's Publishing House.

State Ethnic Affairs Commission, CCCP Party Literature Research Office (1990). Anthology of Literature of Ethnic work in New Era (p. 34). Beijing: Central Literature Press.

Tang, B. (1995). Tibetan People's Contribution to the War of Anti-Japanese. Journal of Northwest Minorities University, 3, 44-47.

Yang, J. X. (2002). Some Issues about Ethnic Development and Ethnic Relationship. North West Minorities Research, 1, 115-119.

Yang, S. L. (2010). Ethnic Interaction and Development. Beijing: Minzu Publishing House.

Zheng, X. Z. (2011). The Feats of Korea Soldiers and Their Feats in People's Liberation War. Minzu Tribune, 8, 49-53.

Zhou, R. H. (1997). Ethnic Minorities in Red Army's Long Match. Journal of Ningxia University, 19, 60-65.

Submit or recommend next manuscript to SCIRP and we will provide best service for you:

Accepting pre-submission inquiries through Email, Facebook, LinkedIn, Twitter, etc.

A wide selection of journals (inclusive of 9 subjects, more than 200 journals)

Providing 24-hour high-quality service

User-friendly online submission system

Fair and swift peer-review system

Efficient typesetting and proofreading procedure

Display of the result of downloads and visits, as well as the number of cited articles

Maximum dissemination of your research work

Submit your manuscript at: http://papersubmission.scirp.org/

Or contact sm@scirp.org 